\title{
Erratum to: Inpatient satisfaction and job satisfaction/stress of medical workers in a hospital with the 7:1 nursing care system (in which 1 nurse cares for 7 patients at a time)
}

\author{
Yuko Fujimura $\cdot$ Hideji Tanii $\cdot$ Kiyofumi Saijoh
}

Published online: 12 July 2011

(C) The Japanese Society for Hygiene 2011

\section{Erratum to: Environ Health Prev Med (2011) \\ 16:113-122 \\ DOI 10.1007/s12199-010-0174-x}

The original version of this article unfortunately contained several errors.

\footnotetext{
Abstract

In the last sentence of the Results section (page 113, left column, lines 23-25), the text should read:

Total percentage profit in 2008 was almost the same as that in 2007, whereas diseases with deficits increased from 3 to 4 .

\section{Results}

In "The profits of the hospital" section (beginning on page 119 , right column), the text should read:

When the profits of the hospital in 2007 under the 10:1 system and in 2008 under the 7:1 system were compared, total percentage profit was the almost the same, being $1.50 \%$ in 2007 and $1.41 \%$ in 2008 (Table 5). In 2007,
}

deficits were observed in 3 diseases, namely acute myocardial infarction, valvular heart disease, and bradyarrhythmia, whereas 4 diseases showed deficits in 2008, namely tachyarrhythmia, valvular heart disease, bradyarrhythmia, and diabetes mellitus, type 2 . In both years, these deficits were covered by the profits of the other diseases.

\section{Discussion}

On page 121, in the right column, the second through fourth sentences of the first paragraph should read:

Total profit of this hospital did not change after introduction of the 7:1 system. However, the percentage profit of 4 of 10 diseases was negative, so that the maintenance of profit was dependent on the profit from the patients with the other 6 diseases. If the number of patients with these 4 diseases exceeded that of patients with the other 6 diseases, the hospital would suffer a financial loss.

In Table 5 there are some errors. The correct version of Table 5 is:

The online version of the original article can be found under doi:10.1007/s12199-010-0174-x.

Y. Fujimura $\cdot$ H. Tanii $\cdot$ K. Saijoh $(\square)$

Department of Hygiene, Kanazawa University School

of Medicine, 13-1 Takara-machi,

Kanazawa 920-8640, Japan

e-mail: saijohk@med.kanazawa-u.ac.jp 
Table 5 Profitability of the hospital for 10 cardiac and metabolic diseases under the 10:1 and 7:1 systems

\begin{tabular}{|c|c|c|c|c|c|c|}
\hline \multirow[t]{2}{*}{ DPC code (disease) } & \multicolumn{3}{|c|}{2007 under the $10: 1$ system } & \multicolumn{3}{|c|}{2008 under the $7: 1$ system } \\
\hline & DPC (points) & Profits (points) & Profits $(\%)$ & DPC (points) & Profits (points) & Profits $(\%)$ \\
\hline 050030 (acute myocardial infarction) & $6,923,681$ & $-121,846$ & -1.76 & $5,391,525$ & 39,132 & 0.73 \\
\hline 050050 (angina pectoris) & $46,813,545$ & $1,274,560$ & 2.72 & $44,147,571$ & $1,037,940$ & 2.35 \\
\hline 050070 (tachyarrhythmia) & $11,016,753$ & 182,988 & 1.66 & $9,884,815$ & $-92,995$ & -0.94 \\
\hline 050080 (valvular heart disease) & $14,696,040$ & $-471,024$ & -3.21 & $17,348,558$ & $-119,970$ & -0.69 \\
\hline 050130 (heart failure) & $7,332,777$ & 560,814 & 7.65 & $9,788,338$ & 542,500 & 5.54 \\
\hline 050170 (arteriosclerosis obliterans) & $4,883,753$ & 38,563 & 0.79 & $5,765,569$ & 91,000 & 1.58 \\
\hline 050210 (bradyarrhythmia) & $4,857,805$ & $-152,912$ & -3.15 & $3,893,559$ & $-132,840$ & -3.41 \\
\hline 100060 (diabetes mellitus, type 1) & 619,893 & 2,116 & 0.34 & 622,816 & 5,983 & 0.96 \\
\hline 100070 (diabetes mellitus, type 2) & $4,602,209$ & 173,418 & 3.77 & $7,340,706$ & $-88,769$ & -1.21 \\
\hline 100140 (hyperthyroidism) & 794,878 & 48,715 & 6.13 & $1,645,274$ & 212,149 & 12.89 \\
\hline Total & $102,541,334$ & $1,535,392$ & 1.50 & $105,828,731$ & $1,494,130$ & 1.41 \\
\hline
\end{tabular}

Profits were calculated as DPC-FFS and percentage profit as profits/DPC. One point is equivalent to 10 yen 